\title{
Checking of New Vocabulary Instruction Improves Iranian Female Intermediate Students' Pronunciation
}

\author{
Hemati Kolavani Fatemeh \\ Department of Human Science, English Guilan University, Rasht, Iran
}

Email address:

Farangis.saeedi@yahoo.com

\section{To cite this article:}

Hemati Kolavani Fatemeh. Checking of New Vocabulary Instruction Improves Iranian Female Intermediate Students' Pronunciation. Education Journal. Vol. 5, No. 4, 2016, pp. 49-52. doi: 10.11648/j.edu.20160504.12

Received: December 20, 2015; Accepted: January 5, 2016; Published: June 30, 2016

\begin{abstract}
Pronunciation is an important concept in Second language learning. In this article at first I selected 30 girl students randomly. They are intermediate level. Then I took an oral exam in order to find their level in pronunciation. Most of the students didn't get good marks. Then during classes, teacher checked students' pronunciation and check instruction of new vocabularies one by one. Students practiced instructions themselves. After that, I got a post-test and calculate differences between post-test and pre-test. At last, I resulted in improving students pronunciation. In conclusion, students can pronounce better by checking instructions.
\end{abstract}

Keywords: Pronunciation, Instruction, Vocabulary

\section{Introduction}

English instructors have to deal with foreign accented speech in their classrooms on a daily basis. Although most have become skillful at interpreting their students' deviant pronunciations, oftentimes small misunderstandings or complete breakdowns in communication still occur in the classroom. Unfortunately, many English teachers do not know how to help students improve their pronunciation in order to prevent, or at least reduce, these communication breakdowns.

One of the key requirements for language proficiency is to secure understandable pronunciation for the language learners. Direct or explicit instruction is hypothesized to result in conscious learning, not subconscious acquisition. If this hypothesis is correct, language acquisition theory predicts that the effect of explicit instruction will appear only when three conditions for the use of conscious learning (Monitor use), are met: When the second language performer (1), consciously knows the rule, (2), has time to think about the rule, and (3), is thinking about correctness, or is focused on form. So far, research results are consistent with these predictions for grammar instruction (Krashen, 1982, 2003).

Pronunciation instruction was absent from the second/foreign language (L2), 1 classroom for a long time due to the conventional beliefs that pronunciation is not important, cannot be taught, and can be "picked up" by learners. These beliefs have been questioned and pronunciation teaching has undergone a shift, so that nowadays, its frameworks mayencompass not only linguistic competence, but also discourse, sociolinguistic, and strategic competence (Morley, 1994).

In this article, we want to study about pronunciation instruction that improve female students' pronunciation. How to improve pronunciation by checking new vocabulary?

\section{Literature Review}

The Saito and Lyster study is the only one that provides possible evidence that instruction can influence the acquisition, and not just the learning, of accent. Thus, the entire case supporting the hypothesis is that instruction and correction can lead to the acquisition of improved pronunciation is based on a single study involving training on one sound, and there are plausible reasons to hypothesize that acquisition did not take place. Follow-up testing, with an even longer period of time between the instruction and the post-test, under conditions where Monitoring is highly improbable can resolve this issue (e. g. areal conversation with people not associated with the pronunciation instruction, with no suggested target words presented). 
Pronunciation instruction is increasingly being recognized as one of the important components of the L2 classroom. As observed by Pennington (1994, p. 105), the value of pronunciation instruction lies in the fact that it can help learners develop their interlanguage phonology by giving them "the perceptual and the productive experience they need to reconceptualize the performance targets while offering motivation to change and social experiences to develop a new value set".

The Direct Method and the Naturalistic Approaches regard the process of learning a L2 as being the same as that of acquiring a L1. Thus, by listening to an appropriate model, L2 learners "pick-up" the pronunciation. Consequently, the methodology for pronunciation teaching consists of imitating a model through repetition, and the imitation can start after an initial "silent period", during which the learner listens to L2 samples, but is not required to speak.

A very popular series in Brazil is Interchange/New Interchange (Richards et al., 1990, 1998). The four books in the series are designed to take learners from the beginning up to the intermediate level. An analysis of books 1, 2 and 3 reveals that the pronunciation component is present in almost all units. The pronunciation tasks are generally very short and simple, consisting of presentation through a model, listening discrimination, identification, repetition, and a few exercises require in $g$ learners' elaboration of examples based on the model.

Most of these procedures, as well as the content (stress, intonation, linking, deletion), are recurrent in the three books, as well as the way they are presented and practiced. What varies is the grammar of the sentences and the vocabulary being practiced, which are directly connected to the unit where the pronunciation task appears.

As regards the pronunciation manuals, most of them are directed at intermediate or advanced learners (Prator \& Robinet, 1985; Orion, 1987; Hagen \& Grogan, 1992; and Gilbert, 1993). Hewings' (1993), manual is the only one directed at Preintermediate learners.

Furthermore, pronunciation materials sometimes ignore other major factors such as the learners' L1. The justification for this might come from the fact that it is not easy to account for every L1 difficulties. Nevertheless, it seems that a motivating environment in the pronunciation classroom depends on working with issues that learners might recognize as being important to improve their pronunciation.

What constitutes a good pronunciation training Study?

As Norris and Ortega (2006), state, a traditional narrative analysis is subject to the biases of its authors; therefore, we clarify here our conception of an ideal pronunciation instruction study (noting that we have yet to conduct any ideal Studies ourselves).

We believe that pronunciation research and instruction should be primarily concerned with helping learners become more understandable. This aligns with Levis' (2005), definition of the Intelligibility Principle, in opposition to the Nativeness Principle, which Levis defines as the notion that 'it is both possible and desirable [for adults] to achieve native-like pronunciation in a foreign language' (p. 370). These two principles are reflected in Munro and Derwing's (1995), tripartite distinction among accent (how different an L2speaker's productions are from a local variety), intelligibility (how understandable L2 speech is), and comprehensibility (how easy L2 speech is for a listener to understand).

An ideal quantitative study should: (i), provide enough detail about participants and procedures to allow replication; (ii), have large enough samples to conduct statistical analyses, including effect sizes; and (iii), employ a control group to verify that improvement is a result of instruction. The latter is especially critical in cases when instruction occurs while learners are newly immersed in their L2 environment-when naturalistic improvement is most likely to happen. Moreover, an ideal study would not limit assessment stimuli measuring learners' pronunciation ability to reading aloud; extemporaneous or spontaneous speech that better reflects natural communication is important. Assessment should also include a delayed posttest to Determine whether the intervention had a lasting effect.

To address concerns regarding ecological validity, the ideal study should be conducted in a classroom - although laboratory research can be extremely informative. If strong evidence of improved intelligibility and comprehensibility is found in language classrooms as a result of pronunciation instruction, more language instructors may be willing to teach pronunciation in systematic and principled ways.

\section{Methodology}

\subsection{Participants}

Participants are 30 female students in an institution. They are in intermediate level from Rasht. I selected them randomly. All of them had a high school education and were placed into language classes according to assessment level.

\subsection{Material}

An English book, oral exam, written pronunciation exam

Procedure: At first, I gave an oral exam that students just pronounced some words. After collecting marks, I concluded that most of them can't pronounce

Short and long vowels. Then, they studied English instruction that explain how to pronounce words. Teacher explained instructions in class intervals. After two weeks, I gave a post test (that is in Appendix). 


\section{Results}

Table 1. Pre-test and post-test marks are stated below.

\begin{tabular}{|c|c|c|c|c|c|c|c|}
\hline pre-test SCORE & mean & $x-m$ & $(\mathrm{X}-\mathrm{M})^{2}$ & pre-test SCORE & mean & $x-m$ & $(\mathrm{X}-\mathrm{M})^{2}$ \\
\hline 5 & 10.5 & -5.5 & 30.25 & 10 & 10.5 & -0.5 & 0.25 \\
\hline 5 & 10.5 & -5.5 & 30.25 & 11 & 10.5 & 0.5 & 0.25 \\
\hline 6 & 10.5 & -4.5 & 20.25 & 11 & 10.5 & 0.5 & 0.25 \\
\hline 6 & 10.5 & -4.5 & 20.25 & 12 & 10.5 & 1.5 & 2.25 \\
\hline 7 & 10.5 & -3.5 & 12.25 & 12 & 10.5 & 1.5 & 2.25 \\
\hline 8 & 10.5 & -2.5 & 6.25 & 12 & 10.5 & 1.5 & 2.25 \\
\hline 8 & 10.5 & -2.5 & 6.25 & 13 & 10.5 & 2.5 & 6.25 \\
\hline 8 & 10.5 & -2.5 & 6.25 & 13 & 10.5 & 2.5 & 6.25 \\
\hline 9 & 10.5 & -1.5 & 2.25 & 14 & 10.5 & 3.5 & 12.25 \\
\hline 9 & 10.5 & -1.5 & 2.25 & 14 & 10.5 & 3.5 & 12.25 \\
\hline 9 & 10.5 & -1.5 & 2.25 & 15 & 10.5 & 4.5 & 20.25 \\
\hline 10 & 10.5 & -0.5 & 0.25 & 15 & 10.5 & 4.5 & 20.25 \\
\hline 10 & 10.5 & -0.5 & 0.25 & 16 & 10.5 & 5.5 & 30.25 \\
\hline 10 & 10.5 & -0.5 & 0.25 & 16 & 10.5 & 5.5 & 30.25 \\
\hline
\end{tabular}

Total (x-m): 0. Total(x-m) 2: 290.

Table 1. Continued.

\begin{tabular}{|c|c|c|c|c|c|c|c|}
\hline post-test SCORE & mean & $\mathbf{x}-\mathbf{m}$ & $(\mathrm{X}-\mathrm{M})^{2}$ & post-test SCORE & mean & $\mathbf{x}-\mathbf{m}$ & $(\mathrm{X}-\mathrm{M})^{2}$ \\
\hline 10 & 15.5 & -5.5 & 30.25 & 17 & 15.5 & 1.5 & 2.25 \\
\hline 10 & 15.5 & -5.5 & 30.25 & 17 & 15.5 & 1.5 & 2.25 \\
\hline 11 & 15.5 & -4.5 & 20.25 & 18 & 15.5 & 2.5 & 6.25 \\
\hline 11 & 15.5 & -4.5 & 20.25 & 18 & 15.5 & 2.5 & 6.25 \\
\hline 11 & 15.5 & -4.5 & 20.25 & 18.5 & 15.5 & 2.5 & 6.25 \\
\hline 12 & 15.5 & -3.5 & 12.25 & 18.5 & 15.5 & 2.5 & 6.25 \\
\hline 12 & 15.5 & -3.5 & 12.25 & 18.5 & 15.5 & 2.5 & 6.25 \\
\hline 12 & 15.5 & -3.5 & 12.25 & 19 & 15.5 & 3.5 & 12.25 \\
\hline 13 & 15.5 & -2.5 & 6.25 & 19 & 15.5 & 3.5 & 12.25 \\
\hline 14 & 15.5 & -1.5 & 2.25 & 19 & 15.5 & 3.5 & 12.25 \\
\hline 14 & 15.5 & -1.5 & 2.25 & 19.5 & 15.5 & 4 & 16 \\
\hline 15 & 15.5 & -0.5 & 0.25 & 20 & 15.5 & 4.5 & 20.25 \\
\hline 15 & 15.5 & -0.5 & 0.25 & 20 & 15.5 & 4.5 & 20.25 \\
\hline 15 & 15.5 & -0.5 & 0.25 & & & & \\
\hline 16 & 15.5 & 0.5 & 0.25 & & & & \\
\hline 16 & 15.5 & 0.5 & 0.25 & & & & \\
\hline 16 & 15.5 & 0.5 & 0.25 & & & & \\
\hline
\end{tabular}

Total: 0. Total: 299.25 .

Table shows that pre-test and post-test scores, standard deviation and Variance. It indicates that there is difference between scores. Scores were increased.

\subsection{Data Analysis}

I use quantitative method in order to analyze data

$$
\mathrm{t}=\frac{\overline{x 1}-\overline{x 2}}{\sqrt{\frac{s 12}{N 1}}+\frac{s 22}{N 2}}
$$

$V=299.25 / 30=9.975 S D=\sqrt{ } 9.975=3.158$

T-test $=5 / 12.81=0.390$

$V=$ variance $s d=$ standard deviation $t$-test=statistic hypothesis test

$N=$ number $m=$ mean $x=$ average

\subsection{Results}

Results indicate the difference between pre-test and post- test score.

So, the difference between pre-test and post-test is: pre $S D=9.66$ Post $S D=9.975$.

\subsection{Findings and Discussion}

Checking instruction is helpful in improving students' pronunciation. Students remind instructions more and more and they practice it.

Keeping in mind helps students to say correct pronunciation. These results demonstrate that even adding only a relatively time-limited explicit pronunciation component in a primarily communicative classroom can lead to beneficial results in production for learners.

\section{Conclusion}

Listening discrimination practice has been shown to not only have a positive effect on learners' perception abilities, but also in their production capabilities of the target feature 
(Rochet, 1995; Wang \& Munro, 2004).

Pronunciation instruction, unlike grammar or vocabulary, however, poses some unique sensory and physiological challenges to learners, as it requires motor control in addition to cognitive mastery. Therefore, teachers need to provide tactile and kinesthetic learning approaches in addition to the traditional rule-based explanations (Celce-Murcia et al., 2010).

These findings suggest that the efficacy of pronunciation instruction is not contingent upon the hours of instruction, or the necessity of an "expert" or native speaker pronunciation teacher, but instead upon the methods and materials used for the instruction.

\section{Appendix}

Choose the best one?

1) The word "---------------"has a different vowel sound from the other three.

a) fool b) soon c) food d) cook

2) The word "................" has a different vowel sound from the other three.

a) pull b) rude c) do d) too

3) The word "..............." has a louder first syllable.

a) myself b), sixteen c), believe d), never

4) The word "................" has a louder second syllable.

a) People b), hobby c) hello d) garden

5) The word "................." has three syllables.

a) Wanted b) sometimes c) building d) remembered

6) Which word ends with /Iz/?

a) Bakes b) moves c), teaches d) writes

7) Which word has stress on the second syllable?

a) Yellow b), dinner c) around d) even

8) The word "-------------“"has a different consonant sound from the other three.

a) Dogs b) foes c), maps d) pens

9) In the word "------------"the stress is on the second syllable.

a) Awake b) happy c), pretty d) simple

10) In the word "------------“"the stress isn't on the second syllable.

a) Umbrella b), dictionary c) eighteen d) complete

11) In the word "------------"the stress is on the first syllable.

a) Chinese b) winter c), enough d) allow

12) In the following group of words the word "

"has the short / $v$ / sound.

a) Wool b) fool c) loose d) tooth

13) The word "-------------"has the / aI / sound.

a) Child b) voice c) hair d) wait

14) Which word has the sound / u: /?

a) Foot b) boot c) cook d) look

15) Which word have a different sound?

a) Fork b), work c), walk d) talk

16) Which word has the sound /a $v /$ ?

a) young b) would c), south d) touch

17) Which word has the sound /a $v /$ ? a) Hpe b), come c) move d), more

18) (comb), a), come b) some c) home d) more

19) (he'll), a) weak), b) hear c) real d) wear

20) (cook), a) put b) cup c) bus d) sun

21) (break), a) treat b) great c) preach d) breath

22) The pronunciation of $(U)$, is like the pronunciation of (U), in....

a) Beauty b) turkey c) ruler d) guide

23) Which word has the sound /u:/?

a) Cool b) soon c) roof d) look

24) The pronunciation of $((\mathrm{ou}))$, in though is like the pronunciation of $((\mathrm{ow}))$, in.........

a) How b) now c) show d), down

25) The $((\mathrm{o}))$, in fork is pronounced like $((\mathrm{oo}))$, in.............

a) Door b) boot c) roof d), cook

26) Which word doesn't have the sound / e:/ ?

a) Burn b) turn c) earn d), worn

27) a) fool b), pool c), wool d), tool

28) a) wear b), hear c), near d), fear

29) The $((\mathrm{ou}))$, in should is pronounced like ((ou)), in...........

a), group b), could c), found d), cloud

\section{References}

[1] Anderson-Hsieh, J. R., \& Koehler, K. (1988). The effect of foreign accent and speaking rate on native speaker comprehension. Language Learning, 38, 561-593.

[2] Anderson-Hsieh, J., Johnson, R., \& Koehler, K. (1992). The relationship between nativespeaker judgments of nonnative pronunciation and deviance in segmental, prosody and syllable structure. Language Learning, 42, 529-555.

[3] Beebe, L. M. (Ed.). (1988). Issues in second language acquisition. Rowley, MA: Newbury House.

[4] Cotterall, S. (2000). Promoting learner autonomy through the curriculum: Principles for designing language courses. ELT Journal, 54, 109-117.

[5] Dörnyei, Z., \& Csizér, K. (2002). Some dynamics of language attitudes and motivation: Results of a longitudinal nationwide survey. Applied Linguistics, 23, 421-462.

[6] Deng, J., Holtby, A., Howden-Weaver, L., Nessim, L., Nicholas, B., Nickle, K., et al. (2009). English pronunciation research: The neglected orphan of second language acquisition studies? PMC Working Paper WPO5-09, The University of Alberta.

[7] Venkatagiri, H., \& Levis, J. (2007). Phonological awareness and speech comprehensibility: An exploratory study. Language Awareness, 16 (4), 263-277.

[8] Wang, X., \& Munro, M. (2004). Computer-based training for learning English vowel contrasts. System, 32, 539-552.

[9] Wennerstrom, A. (1998). Intonation as cohesion in academic discourse. Studies in Second Language Acquisition, 20 (1), 125 . 